\title{
Health sector reforms and changes in prevalence of untreated morbidity, choice of healthcare providers among the poor and rural population in India
}

\author{
Soumitra Ghosh*
}

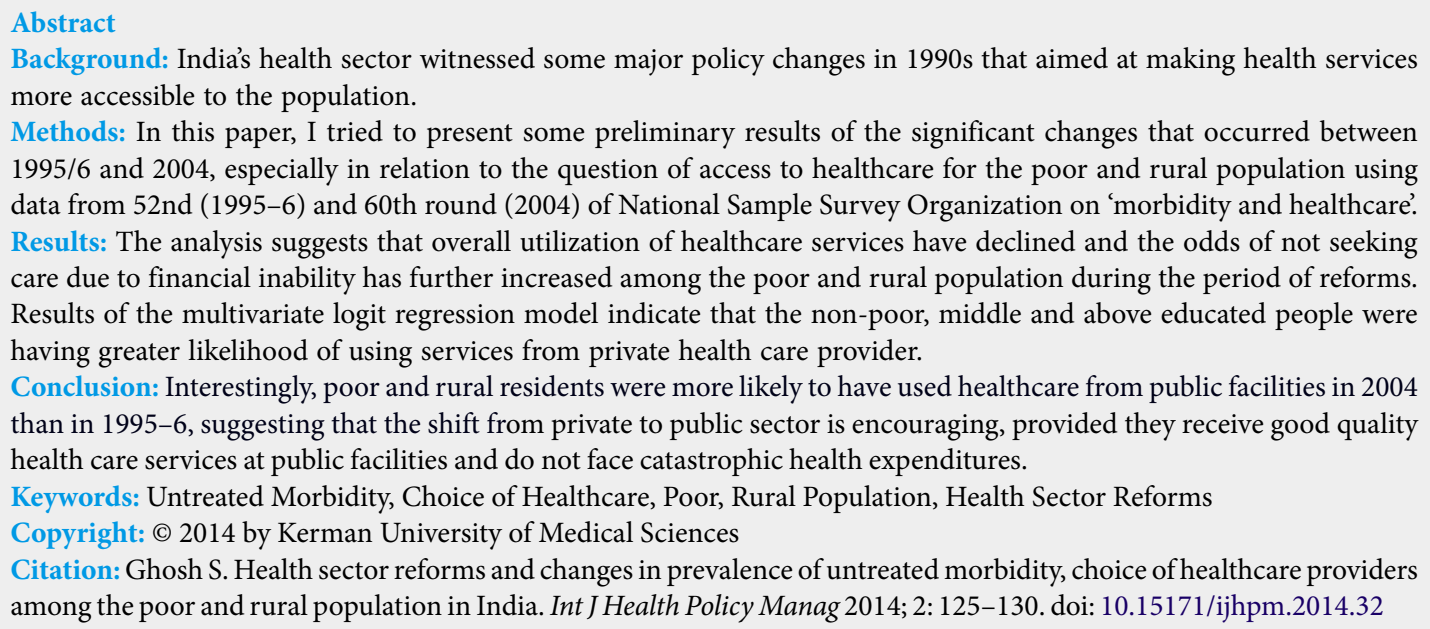

Background: India's health sector witnessed some major policy changes in 1990s that aimed at making health services more accessible to the population.

Methods: In this paper, I tried to present some preliminary results of the significant changes that occurred between $1995 / 6$ and 2004, especially in relation to the question of access to healthcare for the poor and rural population using data from 52nd (1995-6) and 60th round (2004) of National Sample Survey Organization on 'morbidity and healthcare'. Results: The analysis suggests that overall utilization of healthcare services have declined and the odds of not seeking care due to financial inability has further increased among the poor and rural population during the period of reforms. Results of the multivariate logit regression model indicate that the non-poor, middle and above educated people were having greater likelihood of using services from private health care provider.

Conclusion: Interestingly, poor and rural residents were more likely to have used healthcare from public facilities in 2004 than in 1995-6, suggesting that the shift from private to public sector is encouraging, provided they receive good quality health care services at public facilities and do not face catastrophic health expenditures.

Keywords: Untreated Morbidity, Choice of Healthcare, Poor, Rural Population, Health Sector Reforms Copyright: () 2014 by Kerman University of Medical Sciences

Citation: Ghosh S. Health sector reforms and changes in prevalence of untreated morbidity, choice of healthcare providers among the poor and rural population in India. Int J Health Policy Manag 2014; 2: 125-130. doi: 10.15171/ijhpm.2014.32

Article History: Received: 28 December 2013 Accepted: 30 March 2014 ePublished: 2 April 2014

\author{
Correspondence to: \\ Soumitra Ghosh \\ Email: soumitra@tiss.edu
}

\section{Background}

Empirical research has demonstrated that access and use of healthcare depends on several factors such as availability of care, healthcare consciousness of the population, responsiveness of healthcare system, fees charged for healthcare services, and perceived quality of care (1-6).

India made a number of major health policy changes in an attempt to improve access to healthcare services and address the inequity in access to healthcare utilization. Although it was in the 1980s that the state's role in providing healthcare services declined, the real endeavour towards health sector reforms in India began only in the 1990s (7). The health sector reforms have been a gradual process but it resulted in significant changes in the configuration and delivery of healthcare services and healthcare financing (8).

One of the early health sector reform measures was the introduction of user-fees in the public health sector during the eighth five-year plan (1992-7). The case for user-charges has typically been made on grounds that they have potential for mobilizing funds for the cash-strapped India's health sector which would enhance the quality of care, increase utilisation and improve access to health services for the population, especially for the poor (reduce the inequity in access to healthcare). Majority of them initiated these measures during the period mid to late 1990s. Also, during the period late 1990s to early 2000, many states initiated the World Bank sponsored health systems development project, which led to a further increase in the user fees in the public hospitals.
Another major policy reform was the decentralization of healthcare system which was carried out in 1990s as part of the government reform process in the country. The decentralization of governance implied the transfer of authority and responsibility from the central government to the district and lower level to make development more locally sensitive and participatory. As per this new administrative arrangement, local governments have now more say in allocating resources and delivering services (including health) in accordance with the need of the community (9). However, all states did not carry out reform in the same spirit meaning that decentralization of health services was done in a limited manner in many states as the local governments did not have much say when it comes to allocation of resources for the health sector.

Another important policy change was mainly related to the decline of public spending on health during the period of economic liberalization. The reduction on public health expenditure has been affected further at the state level in the 1990 s and first half of 2000s (10). India's public spending on health stood at $0.94 \%$ of GDP in 2004-5. As a result, public sector has failed to cope with the increasing demands of healthcare. The reduction in public health investments coupled with increase in user-fees in the public sector have helped the private sector to fill the space and exploit the market opportunity $(11,12)$. An estimate showed that private sector accounted for nearly four-fifth of the outpatient care services 
and almost half of inpatient care in India (13). This has also happened in line with the emphasis given in the health system reforms to increase the involvement of the voluntary, private players in the provision of healthcare services.

Another major development occurred in the health sector when the macro-economic reforms of 1991 percolated to the Pharmaceutical Industry in 1994 with the introduction of a new Drug Price Control Order (DPCO). According to the DPCO, 1995, out of the 500 bulk drugs, most were taken out of the statutory price control, leaving only 74 (14). The pharmaceutical sector was further liberalized in 2002. The effect of these changes in the drug policy was seen in the steep rise in drug prices during the period 1994 to 2004 (15).

Innately, the developments in the health sector are expected to affect the utilization of healthcare and choice of healthcare providers. Therefore, an assessment of the likely impact of these changes is important for evidence-based policy formulation. In this paper, attempts are made to present some preliminary results of the significant changes that occurred between 1995/6 and 2004, especially in relation to the question of access to healthcare ${ }^{1}$. Secondly, the reasons for not seeking medical treatment are discussed for the study period. Thirdly, analyses are conducted to identify the factors associated with choice of healthcare providers and finally, efforts are made to investigate the income-related inequalities in non-utilization of healthcare in India.

\section{Methods}

The access to healthcare has not received adequate attention from the academia, mainly due to the unavailability of national or state representative household-level data sets. The National Sample Survey Organization (NSSO)'s survey data on 'morbidity and healthcare' is most appropriate for this type of analysis. The survey on the above subject is conducted decennially as part of the nationally representative sample surveys on social consumption by NSSO. The data used for this study were obtained from the two most recent rounds of NSSO$60^{\text {th }}(2004)$ and $52^{\text {nd }}(1995-6)$ which gathered information on socio-economic and demographic characteristics, the morbidity patterns in the population, the utilization of the healthcare services and expenditure incurred for treatment of ailments. A two stage stratified sampling design was adopted in these rounds. While the census villages and urban blocks were the First Stage Units (FSUs) for the rural and urban areas respectively, households were the Second Stage Units (SSUs). The sample for the present study consists of 35368 and 36462 usual members of the households who reported to have suffered from any illness during the last 15 days prior to the survey date for the period 1995-6 and 2004 respectively. As per the field instructions for filling up the survey, medical advice was recorded in those cases where the individual went to a formal healthcare providereither public or private. Since both the 52nd (1995) and 60th rounds (2004) of NSS surveys are based on similar survey design, concepts, definitions and reference period, comparative analysis is plausible.

The poor were identified based on the information collected in the surveys from the households on monthly consumption expenditure. The individuals were identified as being poor whose per capita monthly consumption expenditure was less than the official poverty line for the year $1995-6$ and $2004^{2}$.
Using information on reported morbidity, an indicator variable was constructed for whether an individual had sought care at a formal provider or not. Odds ratios were calculated, using $2 \times 2$ contingency table, for understanding the changes in non-utilization of healthcare among the rural and the poor. For measuring the degree of inequity, inequality in untreated morbidity is standardized for need differences while controlling for non-need variables.

Nonetheless, need is mostly intractable in large-scale surveys and therefore, quantification remains a major challenge $(16,17)$. The perception of health and disease varies according to culture and socio-economic background (18) and hence, the researchers have often relied on demographic characteristics and morbidity indicators for standardization of healthcare need, while controlling for non-need variables like education, social group, region, and so on. Therefore, for adjusting the need differences, the present study utilizes available information on variables such as age, gender, duration of illness and confinement to bed. The last two variables are included to account for the differences in health status. Following the estimation of need-standardized untreated morbidity rate, concentration index is calculated for measuring the magnitude of horizontal inequity (19).

For understanding how different socio-economic and health predictors affect the individual's decision to seek healthcare from a private or public provider in the event of an illness is modelled by applying multivariate binary logistic regression models.

\section{Results}

\section{Levels and trends of untreated morbidity}

Table 1 gives the estimate of the proportion of ailing persons medically not treated for the period 1995-6 and 2004. About 14 and $16 \%$ of the respondents reported that they had not sought care at all in 1995-6 and 2004 respectively, resulting in the odds of not seeking care in 2004 being 1.12 times higher than in 1995-6 ( $\mathrm{OR}=1.12$; 95\% C.I. 1.07-1.17) (Additional file). In 2004, 18 out of 100 persons who reported an illness episode in rural areas did not seek care at all compared to 17 in 1995-6. In urban areas, the corresponding rate was $11 \%$; i.e., $2 \%$ points higher than that in 1995-6.

Although gender differential appears to have leveled in the rural areas, it has widened in the urban areas. Yet, many believe that the NSS data provides an underestimate of female morbidity as other smaller studies report significantly higher rates of untreated morbidity, especially in the reproductive age (20-22). However, rural-urban differential in non-utilization of healthcare has slightly decreased during the period 1995-6 to 2004 because of relatively greater increase in untreated ailments in the urban areas vis-à-vis rural areas for females.

\section{Reasons for not seeking treatment}

To understand why individuals did not seek care when ill, analysis was carried out among those reporting illness, on the reasons for not seeking care. Innately, both supply and demand side factors played an important role for non-utilization of healthcare services. However, the data does not allow for a detailed investigation on this issue, especially not at a disaggregated level. The proportion of those who were unable to access care due to lack of medical facilities has gone up from 9 to $12 \%$ in the rural areas. However, the change was not statistically significant ( $\mathrm{OR}=0.99 ; 95 \%$ C.I. 0.86-1.14) (Additional file). 
Table 1. Rates of untreated ailments by gender and residence, India (\%), 1995-6 and 2004

\begin{tabular}{|c|c|c|c|c|c|c|c|c|c|}
\hline & \multicolumn{3}{|c|}{ Rural } & \multicolumn{3}{|c|}{ Urban } & \multicolumn{3}{|c|}{ Overall } \\
\hline & 1995-6 & 2004 & $\%$ Point change & 1995-6 & 2004 & $\%$ Point change & 1995-6 & 2004 & $\%$ Point change \\
\hline Male & 16 & 18 & 2 & 9 & 10 & 1 & 14 & 15 & 1 \\
\hline Female & 18 & 18 & 0 & 9 & 11 & 2 & 15 & 16 & 1 \\
\hline Person & 17 & 18 & 1 & 9 & 11 & 2 & 14 & 16 & 2 \\
\hline
\end{tabular}

Long waiting as a reason for not seeking care was mentioned by $1 \%$ in 2004 , up from $0.5 \%$ in $1995-6(\mathrm{OR}=1.76$; $95 \%$ C.I. $0.95-$ 3.25). Among the poor, there was marginal change in waiting as a reason for not seeking care in $2004(0.30 \%)$ from the $0.47 \%$ found in 1995-6 (OR=1.73; 95\% C.I. 0.54-5.54).

The decision to seek healthcare services on the event of an illness is also governed by factors such as perceived severity of illness. The proportion of those who did not consider their health problems to be "serious" enough declined considerably both in rural (from $52 \%$ in $1995-6$ to $32 \%$ in 2004) (OR= 0.59; 95\% C.I. $0.53-0.65$ ) and poor population (from 43\% in 1995-6 to $32 \%$ in 2004$)(\mathrm{OR}=0.74$; $95 \%$ C.I. $0.62-0.88)$. The proportion of rural population citing lack of faith for not seeking care was down from $4 \%$ in $1995-6$ to $3 \%$ in 2004 (OR=1.04; 95\% C.I. $0.82-1.33)$. Similarly, among the poor, only $3.5 \%$ cited lack of faith for not seeking care in 2004 as against 5.2\% in 1995-6 $(\mathrm{OR}=0.97 ; 95 \%$ C.I. $0.64-1.45)$.

Financial inability was cited as one of the most predominant reasons for not seeking care by the rural and poor population. The situation seems to be further worsening for the poor and rural population as results suggest that between 1995-6 and 2004, there were $5 \%(39 \%$ in $2004 ; \mathrm{OR}=1.32$; $95 \%$ C.I. $1.10-1.58)$ and $4 \%$ increase in the number of untreated ailing persons because of financial reasons among the poor and rural population $(28 \%$ in 2004; $\mathrm{OR}=1.68 ; 95 \%$ C.I. $1.50-1.89$ ). The proportion of those who cited 'others' reasons for not accessing care has also gone up significantly in the rural areas from $10 \%$ in $1995-6$ to $14 \%$ in $2004(\mathrm{OR}=1.31 ; 95 \%$ C.I. 1.15-1.50). Correspondingly, among the poor, there was significant change in 'others' as a reason for not seeking care in 2004 (15\%) compared to $1995-6$ (9\%) $(\mathrm{OR}=$ 1.43 ; $95 \%$ C.I. $1.11-1.84)$.

Table 2 provides the summary of the data presented in the Additional file. The results suggest that 'access' related issues were not the major reasons for not seeking treatment when needed. Also, the role of 'health consciousness' factors for not utilizing services was found to be on decline during the study period. However, the analysis clearly indicates that 'economic' and 'others' factors were increasingly becoming responsible for the non-use of healthcare by the rural and poor people. And more importantly, the changes in these factors during the period under analysis were found to be statistically significant.

\section{Inequity in untreated ailments}

In order to better understand the changes in inequalities in non-utilization of healthcare, concentration indices are used to measure the Horizontal Inequities (HI) in non-utilization of healthcare after controlling the need and non need factors. Figure 1 shows the concentration curves of India for untreated ailing persons in 1995-6 and 2004. The concentration curves for untreated ailing persons lie below the line of equality indicating that in both 1995-6 and 2004, the distribution of sampled untreated ailing persons is 'pro-poor'. The concentration curve for 1995-6 indicates a greater pro-poor inequality than that of 2004. The associated Concentration Indices (CI) quantify this. The CI for the year 1995-6 was - 0.21 while that of the year 2004 was -0.17 . The concentration curves suggest that the income inequality in the distribution of untreated ailing persons has marginally decreased during the study period.

The rest of the analysis focuses on the kind of care utilized for those reporting an illness. The majority of the rural and poor populations reported having utilized private sector in both periods but the rate of utilization from private sector declined during the period between 1995-6 and 2004 (Figure 2).

Table 2. Odds ratios from two by two tables for reasons for not seeking care by rural residence and the most poor during the period 1995-6 to 2004, India

\begin{tabular}{lll}
\hline Factors & Rural & Most poor \\
\hline Access & & \\
Lack of medical facility & $0.99(0.86-1.14)$ & $0.70^{*}(0.53-0.91)$ \\
Long waiting & $1.76^{*}(0.95-3.25)$ & $1.73(0.54-5.54)$ \\
Health consciousness & & \\
Ailment not considered serious & $0.59 *(0.53-0.65)$ & $0.74 *(0.62-0.88)$ \\
Lack of faith & $1.04(0.82-1.33)$ & $0.97(0.64-1.45)$ \\
Economic & $1.68^{*}(1.50-1.89)$ & $1.32 *(1.10-1.58)$ \\
Financial reason & $1.31 *(1.15-1.50)$ & $1.43^{*}(1.11-1.84)$ \\
\hline Others & & \\
\hline
\end{tabular}

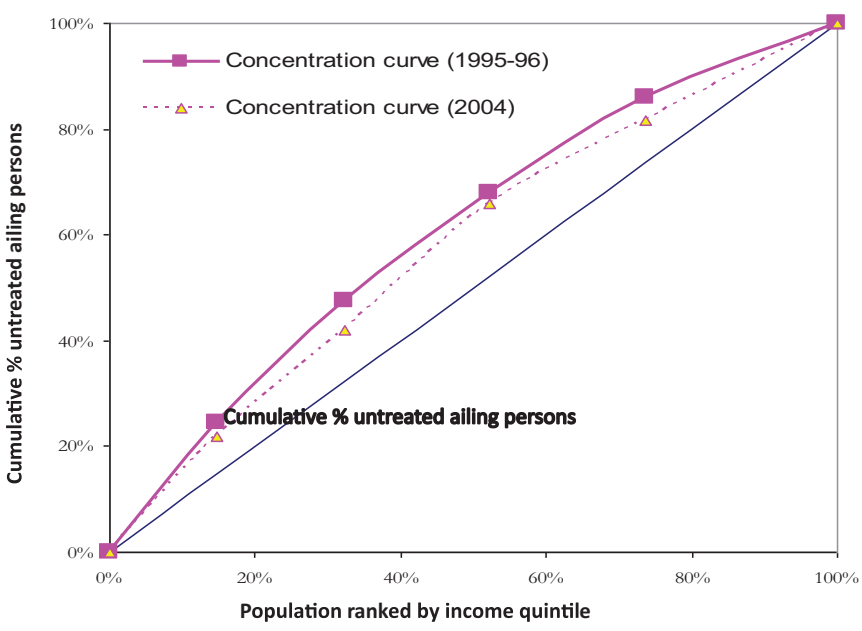

Figure 1. Concentration curve for untreated ailing persons, India, 19956 and 2004 


\section{Choice of healthcare provider}

The probability of choice of care from private or public facilities was modelled using logistic regression. The analysis was restricted to only those who decided to seek healthcare services in the event of an illness. In contrary to the popular notion that there has been a shift in utilization of healthcare from public to private sector, it was observed that people were more likely to have used healthcare from public facilities in 2004 than in 1995$6(\mathrm{OR}=0.68, P<0.001$; Table 3$)$.

The analysis also showed a significant effect of age on choice of provider. The odds of utilizing private source of care is highest among the people aged 45-59 years, followed by aged persons (60 years or more). Gender differences were observed over the study period with women having higher odds of reported utilization of private care $(\mathrm{OR}=1.08, P<0.001)$ than men. Statistically significant association is found between social status and utilization of private source of care.

The use of private source of care is significantly higher among the social groups such as SC, OBC and 'others' compared to 'ST'. The analysis indicates that SES variables are the most important determinants for the choice of healthcare provider. Education exhibited a significant association with choice of private source of care. The individuals with above middle education are found to have higher odds of utilizing care from a private healthcare provider than their illiterate counterparts. The economic status of the individuals is found to be an important determinant for the choice of a private healthcare provider for treatment. The analysis suggests that the likelihood of using private source of treatment is $26 \%$ lower amongst the poor than their non-poor counterparts.

\section{Discussion}

The findings of the study clearly pointed to the problems of access to care, in the event of illness for the poor and rural population during the period of health sector reforms in India. The analysis

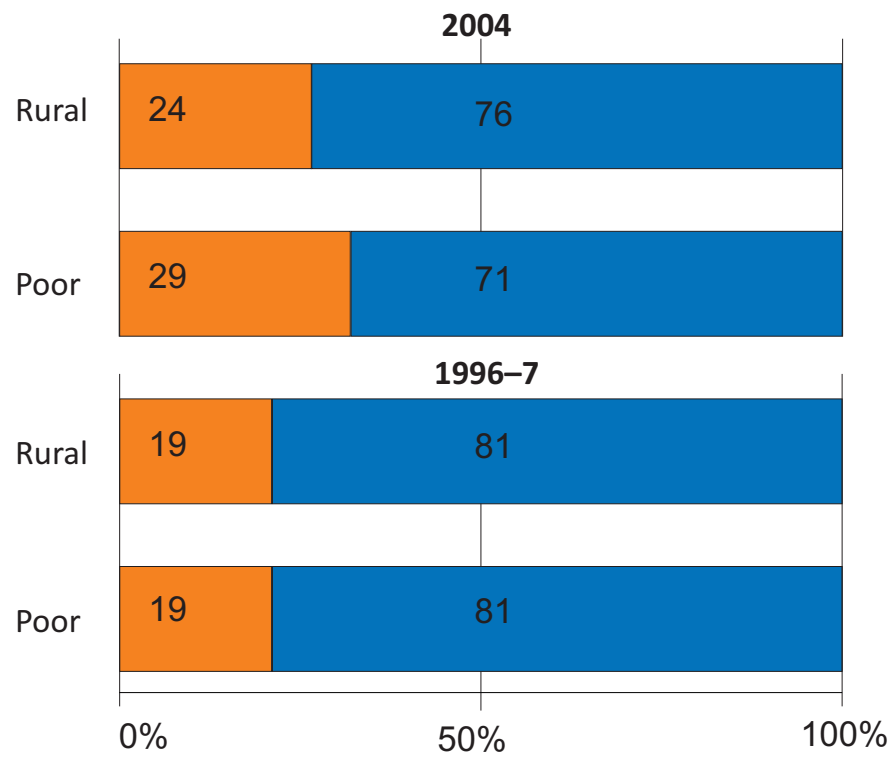

Public a Private

Figure 2. Utilization of outpatient care from public and private healthcare providers amongst the users by rural and poor population, India, 1995-6 and 2004
Table 3. Results of logistic regression on choice of health care provider, India, 1995-6 to 2004

\begin{tabular}{|c|c|c|c|}
\hline Background characteristics & Odds Ratio & $P$ value & 95\% C.I \\
\hline \multicolumn{4}{|l|}{ Age } \\
\hline \multicolumn{4}{|l|}{$0-14^{a}$} \\
\hline $15-29$ & $0.85^{*}$ & 0.000 & $0.80-0.91$ \\
\hline $30-44$ & $0.81 *$ & 0.000 & $0.76-0.86$ \\
\hline $45-59$ & $0.74 *$ & 0.000 & $0.70-0.79$ \\
\hline $60+$ & $0.78^{*}$ & 0.000 & $0.74-0.83$ \\
\hline \multicolumn{4}{|l|}{ Gender } \\
\hline \multicolumn{4}{|l|}{ Male $^{a}$} \\
\hline Female & $1.08^{*}$ & 0.000 & $1.04-1.13$ \\
\hline \multicolumn{4}{|l|}{ Household size } \\
\hline \multicolumn{4}{|l|}{$\leq 4^{\mathrm{a}}$} \\
\hline $5-6$ & 1.00 & 0.991 & $0.95-1.05$ \\
\hline $7+$ & $1.12^{*}$ & 0.000 & $1.06-1.17$ \\
\hline \multicolumn{4}{|l|}{ Social Group } \\
\hline \multicolumn{4}{|l|}{$\mathrm{ST}^{\mathrm{a}}$} \\
\hline SC & $2.15^{*}$ & 0.000 & $1.98-2.33$ \\
\hline Others & $2.62 *$ & 0.000 & $2.43-2.82$ \\
\hline \multicolumn{4}{|l|}{ Education $^{\mathrm{b}}$} \\
\hline \multicolumn{4}{|l|}{ Illiterate ${ }^{a}$} \\
\hline Literate up to middle & 1.01 & 0.595 & $0.96-1.06$ \\
\hline Above Middle & $1.24^{*}$ & 0.000 & $1.17-1.32$ \\
\hline \multicolumn{4}{|l|}{ Poverty status } \\
\hline \multicolumn{4}{|l|}{ Non poor ${ }^{a}$} \\
\hline Poor & $0.76^{*}$ & 0.000 & $0.72-0.81$ \\
\hline \multicolumn{4}{|l|}{ Region } \\
\hline \multicolumn{4}{|l|}{ East $^{a}$} \\
\hline West & $1.94^{*}$ & 0.000 & $1.80-2.09$ \\
\hline North-central & $1.66^{*}$ & 0.000 & $1.57-1.76$ \\
\hline North & $0.85^{*}$ & 0.000 & $0.80-0.91$ \\
\hline South & 1.05 & 0.050 & $0.99-1.11$ \\
\hline \multicolumn{4}{|l|}{ Residence } \\
\hline Rural & 0.93 & 0.001 & $0.89-0.97$ \\
\hline \multicolumn{4}{|l|}{ Urban $^{a}$} \\
\hline \multicolumn{4}{|l|}{ Confinement to bed (Days) } \\
\hline \multicolumn{4}{|l|}{ Not Confined to bed ${ }^{a}$} \\
\hline $1-3$ & 0.92 & 0.009 & $0.86-0.98$ \\
\hline $4+$ & 0.80 & 0.000 & $0.76-0.85$ \\
\hline \multicolumn{4}{|l|}{ Time } \\
\hline \multicolumn{4}{|l|}{$1995-6^{a}$} \\
\hline 2004 & $0.68^{*}$ & 0.000 & $0.65-0.71$ \\
\hline Pseudo-R2 & & 0.0374 & \\
\hline -Loglikelihood & & 31012.037 & \\
\hline
\end{tabular}

${ }^{a}$ Reference category of the variable in logistic regression analysis.

${ }^{b}$ Education refers to the own education (highest grade attained) for individuals over 16 years, while younger individuals are assigned the highest grade attained by any household member.

${ }^{*} P<0.001$

Note: Dependent variable: whether sought care from private facilities in the event of an illness. 
has shown that prevalence of untreated morbidity increased significantly during the period $1995-6$ to 2004 with rural population reporting higher prevalence of untreated illnesses than their urban counterparts. Further, it can be argued that in the Indian context, true levels of untreated morbidity could be much higher because a large share of morbidities is undiagnosed or unreported in illiterate and poor population (23).

Financial barriers are cited as the most important reason for not seeking care in the event of an illness. More importantly, results suggest that during the period when most of the reform initiatives were implemented, the percentage of people not getting treated because of financial reasons has increased, particularly amongst the rural and poor population. Therefore, these findings lend further empirical weight to the anecdotal evidence that the poorest of the poor are increasingly finding it difficult to access health services even from the public sector where the services are supposed to be 'free' for them. The plausible reasons could be the poor targeting of 'user-fees' exemption policy (24), increase in price of medicine and the opportunity cost associated with the visit to the public health facilities (25).

Greater public investments are required for addressing financial needs of the poor for accessing healthcare. For the first time, there has been some policy response to address this phenomenon with the introduction of a subsidized national health insurance scheme that aims to cover all Below Poverty Line (BPL) households in the unorganized sector. However, this would only partially solve the problem as the services under this scheme are restricted to hospitalization episodes within the family, meaning that non-hospitalized morbidities would still remain untreated.

The distribution of untreated morbidities continued to be concentrated among the poor people. However, it is found that the economic differences in not accessing healthcare have slightly narrowed down during the period under study implying that even the non-poor are facing financial barriers for accessing healthcare. The analysis has also shown that private sector has remained the predominant healthcare provider in spite of the presence of the wide network of public healthcare facilities across the country. This could potentially alter the standard of living of a section of the population, especially the poor as they may be subjected to high out-of-pocket health expenditure for accessing services from private sector, raising serious concerns especially for the poor (26).

There is a great need to regulate the private healthcare market, given that majority of the people including the poor rely on private providers. The healthcare providers are highly heterogeneous in the market consisting of private, for profit and not-for-profit providers. One of the special characteristics of this market is that it is highly segregated and the issues faced by the population groups are different. While the lower end of the market comprising of faith healers, semi-qualified practitioners and small hospitals cater to the healthcare need of the low income population, the upper end dominated by corporate hospitals basically serves the middle and high income population. Measures need to be taken to ensure that people receiving care from private providers are of acceptable standard and protocols have to be formulated in order to ensure uniformity in treating patients for similar conditions across private healthcare providers. Efforts should also be made to address issues relating to the large price variations of services, moral hazard behavior of the providers and impose greater social accountability on private providers, making a certain proportion of the services available to the poor.

The poor and rural people were more likely to have used public facilities than private facilities in 2004 than in 1995-6. The finding that public health facilities started to account for a larger share of utilization, especially for the most poor, is heartening if it can be ensured that they receive good quality healthcare at public facilities and reduce catastrophic health expenditures. In fact, government of India has responded to this real opportunity provided by reforms for further consolidating this trend by making larger public investment through National Rural Health Mission (NRHM) (27). The preliminary data from NRHM indicate improvements across dimensions of rural healthcare delivery. The gain in the quality of care provided by public facilities is expected to retain and attract the poor and rural folks, reducing the prevalence of untreated ailments among them.

\section{Endnotes}

${ }^{1}$ In this article, utilization of healthcare services, or access are reported ex-post (after the fact).

${ }^{2}$ The poverty line for 2004 represents the official poverty line given by Planning Commission of India separately for states and regions (rural and urban areas) for the year 2004-5. However, we calculated the growth rate of the price changes during the period $1987-8$ to $1993-4$ and used this to project the poverty line for the year 1995-6 based on the official poverty line for the year 1993-4.

\section{Ethical issues}

Not applicable.

\section{Competing interests}

The author declares that he has no competing interests.

Author's contribution

SG is the single author of the manuscript.

\section{Additional file}

Additional file: Contains the appendix 1.

\section{References}

1. Lindelow M. The Utilization of Curative Health Care in Mozambique: Does Income Matter? [internet]. 2003. Available from: http://www. economics.ox.ac.uk/Centre-for-the-Study-of-African-EconomiesSeries/the-utilization-of-curative-health-care-in-mozambiquedoes-income-matter

2. Mbatia PN, Bradshaw YW. Responding to Crisis: Patterns of Health Care Utilisation in Central Kenya Amid Economic Decline. Afr Stud Rev 2003; 46: 69-92.

3. Sarma S, Simpson S. A micro-econometric analysis of Canadian health care utilisation. Health Econ 2006; 15: 219-39.

4. Trivedi PK. Patterns of health care utilization in Vietnam: analysis of 1997-98 Vietnam Living Standards Survey Data [internet]. 2002. Available from: http://elibrary.worldbank.org/doi/ book/10.1596/1813-9450-2775

5. Mwabu G, Ainsworth M, Nyamete A. Quality of medical care and choice of medical treatment in Kenya: an empirical analysis. J Hum Resour 1993; 28: 838-62.

6. Paul G, Locay L, Sanderson W, Dor A, van der Gaag J. Health Care Financing and the Demand for Medical Care (LSMS Working Paper). Washington, DC: World Bank; 1990.

7. Government of India. Health Sector Reforms in India: Initiatives from Nine States. New Delhi: Directorate General of Health Services, Ministry of Health and Family Welfare; 2003.

8. Sen G, lyer A, George A. Structural Reforms and Health Equity: A Comparison of NSS Surveys, 1986-87 and 1995-96. Econ Polit 
Wkly 2002; 37: 1342-52.

9. Sekher TV, Bhide S, Islam MN, Das Gupta M. Public Health and Panchayati Raj Institutions in Karnataka. Bangalore: Institute for Social and Economic Change; 2006.

10. Mooij J, Dev M. Social sector priorities: an analysis of budgets and expenditures in India in the 1990s. Dev Policy Rev 2002; 22: $97-120$.

11. Peters DH, Yazbeck AS, Sharma RR, Ramana GNV, Lant $H$. Pritchett and Adam Wagstaff. Better Health Systems for India's Poor: Findings, Analysis and Options. Washington, DC: World Bank; 2002.

12. Bhat R. Regulation of the private health sector in India. Int J Health Plann Manage 1996; 11: 253-74.

13. National Sample Survey Organisation (NSSO). Morbidity and Treatment of Ailments. New Delhi: Ministry of Statistics and Programme Implementation; 1998.

14. Government of India. Drugs (Prices Control) Order 1995. Department of Chemicals and Petrochemicals. Bombay: Organisation of Pharmaceutical Producers of India; 1996.

15. National Commission on Macroeconomics and Health (NCMH). Financing and delivery of health care services in India. New Delhi: Government of India; 2005.

16. Culyer AJ. Need: The Idea Won't Do-But We Still Need It. Soc Sci Med 1995; 40: 727-30.

17. Culyer AJ, Wagstaff A. Equity and Equality in Health and Health Care. J Health Econ 1993; 12: 431-57.

18. Murray CJL, Chen LC. Understanding morbidity changes. Popul Dev Rev 1992; 18: 481-503.
19. Ghosh S. Equity in the utilzation of healthcare services in India: evidence from National Sample Survey. Int J Health Policy Manag 2014; 2: 29-38.

20. Madhiwala N, Nandraj S, Sinha R. Health of households and women's lives: study of illness and child bearing among women in Nashik district. Mumbai: Centre for Enquiry into Health and Allied Themes; 2000.

21. Bhatia J, Cleland J. Determinants of maternal care in a region of India. Health Transit Rev 1995; 5: 127-42.

22. Bang RA, Bang AT, Baitule M, Choudhary $Y$, Sarmukaddam S, Tale O. High prevalence of gynaecological diseases in rural Indian women. Lancet 1989; 1: 85-8.

23. Ghosh S, Arokiasamy P. Emerging patterns of reported morbidity and hospitalisation in West Bengal, India. Glob Public Health 2010 5: 427-40.

24. Thakur H, Ghosh S. User-fees in India's health sector: Can the poor hope for any respite? Artha Vijnana 2009; 51: 139-58.

25. Sodani PR, Kumar RK, Srivastava J, Sharma L. Measuring patient satisfaction: a case study to improve quality of care at public health facilities. Indian J Community Med 2010; 35: 52-6.

26. Ghosh S. Catastrophic payments and impoverishment due to out of pocket health spending. Econ Polit Wkly [serial on the internet]. 2011. Available from: http://www.epw.in/special-articles/ catastrophic-payments-and-impoverishment-due-out-pockethealth-spending.html

27. Government of India. National Rural Health Mission Document New Delhi: Ministry of Health and Family Welfare; 2005.

\section{Key Messages}

\section{Implications for policy makers}

- The finding that public health facilities started to account for a larger share of utilization, especially for the most poor, is heartening if it can be ensured that they receive good quality healthcare at public facilities. This would require commitments from government for greater investments in public sector.

- Given that majority of the people including the poor rely on private providers, measures need to be taken to ensure that people receiving care from private providers are of acceptable standard and protocols have to be formulated in order to ensure uniformity in treating patients for similar conditions across private healthcare providers.

- In light of the evidence during the period under analysis, 'pro-poorness' and 'pro-rural populationness' need to be embedded in the proposed universal healthcare programs with a policy bias in favour of the poor and rural population for ensuring equitable access to healthcare.

\section{Implications for public}

The study shows that the level of reported untreated ailments increased during the period 1995-6 to 2004. The fact that during the study period when many important changes took place in the health policy domain, a greater number of rural and poor people cited financial constraints as one of the most predominant reasons for not seeking care compared to 19956 is a matter of great concern. Moreover, it appears that even the number of non-poor persons facing financial barriers for utilizing healthcare increased substantially over the study period. The analysis of healthcare utilisation patterns suggests that the poor and rural persons were more likely to have used public facilities than private facilities in 2004 than in 1995 6 . This is an encouraging trend if it can be ensured that they receive good quality healthcare at public health facilities without experiencing financial hardships. 